\title{
Are Credit Default Swaps Credit Default Insurances?
}

Christian Schmaltz, Aarhus University, Denmark \& True North Institute, UK

Periklis Thivaios, University Of The Witwatersrand, South Africa \& True North Partners, UK

\begin{abstract}
No, they are not. Although they exhibit similar cash flow patterns (economic perspective) this article argues that from a legal, accounting and regulatory perspective credit default swaps $(C D S)$ are not considered to be an insurance contract. The protection buyer of a CDS is eligible to obtain the compensation without suffering any loss (and potentially realizing a gain) whereas insurance policies only pay out to compensate a loss (and not potentially realizing a gain). This disconnect between protection and exposure is the source for potential over-coverage. Furthermore, the concentrated set of reference entities and (interbank) counterparties as well as their tradeability make CDS highly systemically significant products. Our conclusion is that CDS are not default insurance policies and their systemic risk potential sharply contrasts the limited systemic risk in the insurance industry. We propose to use "default protection" instead of "credit default insurance" to avoid the mislabelling. The legal classification of CDS as insurance contracts would have an enormous impact on the liquidity of CDs, as the ability of counterparties to issue and participate in CDS contracts would be limited.
\end{abstract}

Keywords: Credit Default Swaps; Insurance Contract; Credit Default Insurance

\section{INTRODUCTION}

\subsection{Motivation}

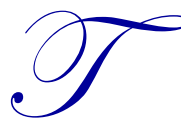

he instrument category "CDS" is a rather recent financial innovation with an impressive growth path as Figure 1 suggests: between 2004 and 2007, the market size multiplied by nine.

Since the beginning of the financial crisis we have observed a decline in CDS notional amounts mainly due to lowered lending dynamics and trade netting. Recently volumes are picking up again due to increased sovereign credit risk.

Despite its impressive growth, it is only recently that CDS have been pulled out of their expert niche to a broader audience due to their involvement in the financial crisis. First, excessive selling of CDS has been the main reason for the financial distress and subsequent \$ 182 billion bailout of AIG. Secondly, premiums of sovereign CDS are used by journalists to measure the severity for the sovereign debt crisis.

Plotting the number of articles that contain the term "Credit Default Swap" in the "Financial Times", "The Guardian" and "El Pais", Figure 2 confirms that "Credit Default Swaps" have gained in public awareness since the outbreak of the crisis. In fact, prior to the financial crisis only specialised newspapers like "The Financial Times" account for a substantial number of articles that contain "Credit Default Swaps". The financial crisis intensified the

\footnotetext{
1 "The Financial Times" has been chosen as a representative for a newspaper specialised in financial topics. The Wall Street Journal has been considered but the Online Search is only accessible for subscribed readers. "The Guardian" and "El Pais" have been chosen to represent nonspecialised newspapers. "El Pais" has been chosen to represent a country with sovereign concerns.
} 
reporting on these instruments such that also newspapers with a more general profile like "The Guardian" and "El Pais" have started mentioning Credit Default Swaps in their articles

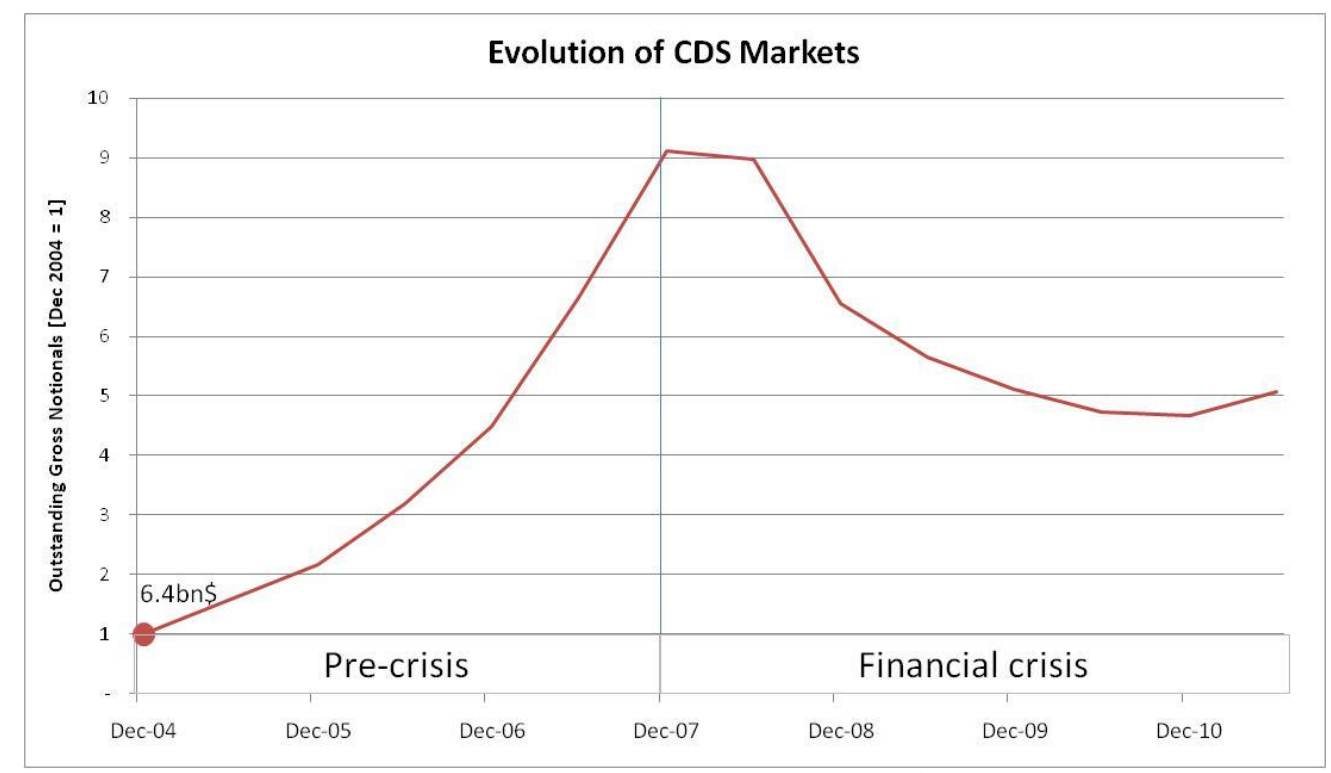

Figure 1: Evolution Of CDS Volumes ${ }^{2}$

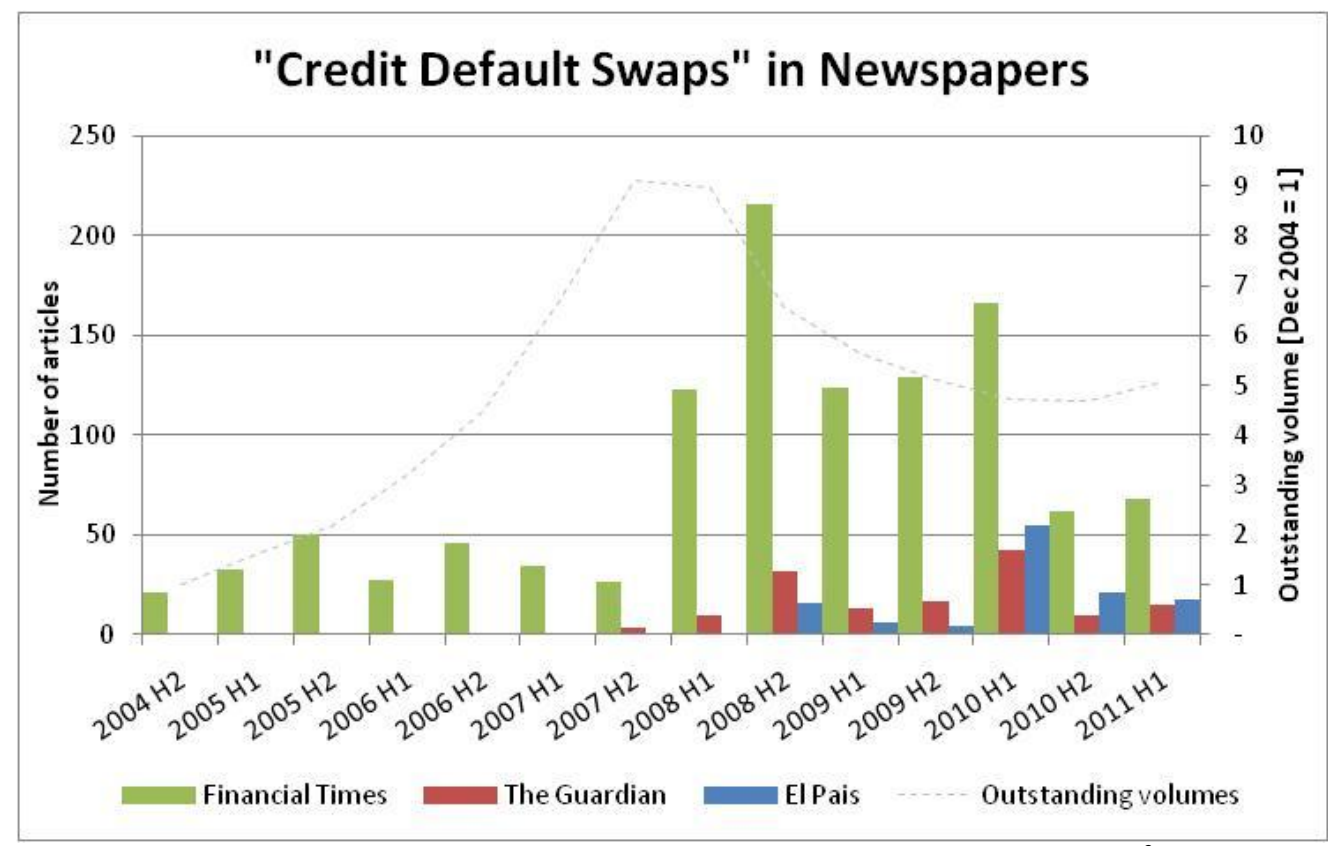

Figure 2: Number Of Articles Containing The Term "Credit Default Swap"3

If the journalist feels that theirs readers might need an explanation for the term "credit default swap" they often use the term "default insurance" (English), "Seguro de impago" (Spanish) or "Kreditausfallversicherung" (German) as the following quotes suggests:

\footnotetext{
2 "OTC derivatives market activity in the first half of 2011", November 2011, Bank for International Settlements (BIS), BIS only started to record CDS data after achieving a critical volume.

${ }^{3}$ Using the search engines on the corresponding websites. For "El Pais" we used "CDS" instead of "Credit Default Swap" because many articles only use the abbreviation in English and a Spanish translation for the long form .
} 
“...ensuring that credit default insurance doesn't pay out, ...."

"... those purchasing default insurance in credit default swap (CDS) markets."

“... la importancia del mercado de seguros de impago (los denominados CDS), ...",

“... Preise für fünfjährige Kreditausfallversicherungen (CDS) ...",

In fact, $3 \%$ of the "Financial Times"- and "The Guardian"-articles that contain "credit default swap" also contain "default insurance". For "El Pais", almost every article that contains "CDS" also contains "seguro", the Spanish word for "insurance".

This article argues that from a legal, accounting and regulatory perspective CDS are not "insurance contracts". Economically, CDs can be equivalent to default insurance in the rare cases that the CDS buyer also holds the illiquid reference debt that underlies the CDS. If journalists use "default insurance" they generalise from this particular set of CDS to "all CDS" and from economic equivalence to legal, regulatory and accounting equivalence, which is clearly inappropriate. Achieving awareness for the mislabelling is one objective of our article.

Not only journalists reiterate on CDS as insurances, but also regulators (e.g. the National Conference of Insurance Regulators in the US) revived the debate by proposing to regulate certain CDS as insurance contracts. ${ }^{8}$

However, due to the lack of an insurable interest, their tradeability, intra-sector concentration and collateral requirements, CDS portfolios exhibit a completely different economic profile than portfolios of insurance claims at the entity level (entity risk) and at the sector level (systemic risk). Showing these differences is the second objective of our article.

The conclusion of the article therefore is that labelling CDS as "default insurance" is inadequate, but for a negligible subset of the instrument. In other words, an unrestrictive equality statement between CDS and insurance contracts is not correct.. We propose replacing the term "insurance" by "protection" thus using "default protection" instead.

\subsection{Related Literature}

Our paper addresses the question whether CDS are insurance contracts from a legal, accounting, regulatory and economic point of view. We challenge the common labelling of CDS as "default insurances". The question of the insurance character of CDS has already been legally addressed and negatively answered by the so-called Potts opinion in 1997 for UK law. ${ }^{9}$ We follow this opinion for our legal discussion, but also consider the recent critique raised by (Juurikkala, 2011) objecting that insurable interest is not a constituent factor for insurance contracts. In our economic analysis, we take the discussion by $(\mathrm{Ng}, 2010)$ on the economic effects of CDS, financial guarantee and credit insurance as a starting point but go beyond that by discussing the implications of tradeability, markt-to-market valuation, margin calls and intra-sector deals for the risk profile of single entities and the banking sector.

\subsection{Contribution}

Our contribution is threefold. Firstly, we discuss the demarcation of CDS vs. insurance contracts across four different dimensions: legal, accounting, regulation and economic. Other authors only consider the legal dimension (Potts), mix legal and regulatory dimension (Juurikkala, 2011) or do not discuss risk issues implied by the economic differences $(\mathrm{Ng}, 2010)$. The separation of the four different dimensions enables us to identify which CDS deals and in which dimension (legal, accounting, regulation, economic) could be seen equivalent to an insurance contract. Secondly, we propose the correct labelling of CDS along the four dimensions. In particular we propose to state: CDS are "default protection" assuming that readers usually relate "are" to the legal dimension. If someone

4 "ECB is playing a dangerous game", The Guardian, December $16^{\text {th }}, 2011$,

5 "Sovereign risk: are the dangers fading?", The Financial Times, March 9, 2010.

6 "Guía fácil para una crisis de deuda", El Pais, June 21, 2011.

7 "Preis für griechische CDS klettert weiter", Handelsblatt, May 19, 2011.

${ }^{8}$ See (Juurikkala, 2011).

${ }^{9}$ See (Harding, 2004), p. 19. 
wants to use "default insurance" to explain CDS, we propose to use "CDS work like default insurance if the protection buyer also holds the reference debt" assuming that readers usually relate "working like" to the economic dimension. Thirdly, we show that other economic aspects imply a completely different risk profile on the entity- and the sector level for CDS portfolios than for portfolios of insurance contracts.

\subsection{Structure}

The remainder of our paper is structured as follows: in section 2 we discuss the legal dimension. Section 3 accommodates the accounting and regulatory dimension. Section 4 encompasses the economic dimension with its implications for the risk profile on entity and sector level. Section 10 concludes.

\section{LEGAL ANALYSIS}

If CDS were insurance contracts, the legality of such instruments that have not been sold by insurance companies (but e.g. by banks) would be questionable. ${ }^{10}$

To analyse the legal character, intuition suggests the following approach: first, to take the legal definition of "insurance" and to show that not all criteria are fulfilled for CDS. Secondly, to take the legal definition of CDS and to show that not all criteria are fulfilled by insurance contracts.

The intuitive way is hampered because the majority of jurisdictions do not have a strict definition of insurance contracts. ${ }^{11}$ Also, there is no binding legal definition of CDS as the term "CDS" is not patented.

\subsection{Insurance Contract}

According to the literature ${ }^{12}$, valid insurance contracts are regularly characterised by three constituent criteria: 1. Payment, 2. Uncertainty and 3. Insurable Interest. ${ }^{13}$

A potential definition around these three criteria would read as follows: firstly, one party (the insurer) promises to make a payment to the policyholder upon a specified future event. Secondly, whether the event happens, or at least when it will happen, must be uncertain. Thirdly, the payment is only made if the event adversely affects the policy holder. Due to the obligation to potentially make the compensation payment, the insurer assumes a risk from the policyholder and requires a premium for it.

\subsection{Credit Default Swaps (CDS)}

The large majority of CDS are contracted within the Master Agreement of the International Swaps and Derivatives Association (ISDA). The Master Agreement identifies each derivative that falls within the agreement and specifies common terms that will be used in all future deals of this product like jurisdiction, covenants and termination clauses. Individual deals are later legally specified by the deal confirmation. The type of (standard) instruments is not (re-)defined in each confirmation but the confirmations usually refer to the ISDA-credit derivative definitions. This leads to a standardisation of instruments. Once the type of instrument is defined, the confirmation lists the type-specific parameters for the deal in question ${ }^{14}$.

At its simplest form, a CDS is structured as follows: a party, the "protection seller", promises to make a lump-sum payment to another party, the "protection buyer", upon the occurrence of a predetermined credit event.

\footnotetext{
${ }^{10}$ See (FSA, 2002), Annex B, p.3.

${ }^{11}$ No strict definitions exist in English law (FSA, The Perimeter Guidance Manual, 2012), p.4 and US-law (Baranoff, Brockett, \& Kahane, 2009), p.123.

${ }^{12}$ See (Juurikkala, 2011),

${ }^{13}$ The three criteria constitute the smallest set of common criteria. Some jurisdictions (like Germany) also add as a fourth criterion that "the premiums are calculated upon a pooling mechanism, i.e. the law of large numbers".

${ }_{14}$ Parameters for a CDS are among others notional amount, maturity, upfront payment (or premium), reference entity debt, covered credit event(s).
} 
The credit event could be the bankruptcy, default, credit rating downgrade etc of a reference entity (e.g. an organisation), a reference obligation (e.g. a bond) or a basket of either of the two; in addition, the trigger could be the non-payment of a coupon or any other similarly structured event. In return, the protection buyer pays the protection seller a periodic fee, usually expressed as a percentage (basis points) of an agreed "notional amount".

\subsection{CDS vs. Insurance Contract}

The question whether CDS constitute an insurance contract or not has already been addressed by a paper written by Mr Robin Potts QC in 1997 and sponsored by the ISDA (referenced in (Ng, 2010)). According to the Potts Opinion (which, as the title suggests, is merely an opinion and not a law), "credit default options plainly differ from contracts of insurance in the following critical respects:

(1) The payment obligation is not conditional on the payee's sustaining a loss or having a risk of loss;

(2) The contract is thus not one which seeks to protect an insurable interest on the part of the payee. His rights do not depend on the existence of any insurable interest."

Potts concludes that CDS are not insurance contracts because the 'sustained loss' is not part of the contract and therefore not a contractual prerequisite for the payment.

The protection buyer would sustain a loss if s/he holds a claim against the reference entity in the moment of default. CDS bought to hedge against an existing exposure are called "covered" CDS. CDS bought without any exposure are called "uncovered" ${ }^{15}$ CDS. Hence, the joint position of a claim against the reference entity plus the CDS would be economically equivalent to an insurance contract. However, it is not legally equivalent, because the CDS contract would continue to be valid even if the claim would have been sold or matured. If it were not only a 'covered' position, but additionally the claim existed during the CDS' lifetime with certainty (not matured and not sellable - a loan would be an example for such a claim), this CDS may well have been a valid insurance contract under UK law. ${ }^{16}$ Potential ambiguities result from the fact that both insurance contracts and CDS are based on a minimum of constituent criteria to accommodate new insurance - or CDS - products in the future. Potts already anticipated the ambiguity on the insurable interest criterion and thus recommended to include a contract clause that the CDS parties '.. do not intend to enter an insurance contract'. However, as (Juurikkala, 2011) notes the expressed intention is not determinant for the nature of the contract. What is determinant is the real intention. The case of the illiquid reference debt is - without further considerations - legally seen as an insurance contract even if the parties state that none of them had the intention to enter such an insurance contract.

In order to remove any ambiguity for CDS positions that are legally close to be an insurance, it is clear that a legal clarification is needed that explicitly states that credit default swaps are not insurance contracts. In the US the Dodd-Franck Act explicitly states that swaps shall not be considered as insurance under any state law. ${ }^{17}$ Under UK law, this clarification has not been made. However, the large majority of CDS is legally not insurance contracts on the grounds of not having an insurable interest (see Potts opinion). For a very small portion with illiquid reference debt, an exemplary case would bring final clarification. So far, the Potts opinion has not been challenged (and refuted) at court such that no CDS has ever been determined to be an insurance contract. CDS with illiquid reference debt would have to be classified as insurance contract if (i) someone brings such a case to court, (ii) the court overrules the "non-insurance intention", (iii) the court judges the illiquid reference debt and the CDS as one legal package and (iv) the court finally concludes that it has an insurance character. If the court construes the CDS with illiquid reference debt as an insurance contract, the contract would be void if sold by a non-insurance entity. If the court confirms that it is a non-insurance contract, legal uncertainty is removed for all CDS under UK law.

Although CDS are legally not seen as insurance contracts, an insurance product does exist for credit risk: the credit insurance. ${ }^{18} \mathrm{~A}$ credit insurance is a contract where the insurer promises to pay the insured trade receivable

\footnotetext{
${ }^{15}$ The term "naked" CDS-position is alternatively used for "uncovered" CDS position.

${ }^{16}$ See (FSA, 2002), Annex B, p.2.

${ }^{17}$ See Dodd-Franck Act, Title VII, Subtitle A, Part II, §722(b) and \$767.

${ }^{18}$ The world's largest credit insurance provider, Euler Hermes, is part of Allianz Group and contributed to 4.50\% of (net) premiums earned in 2010. See (Allianz, 2010), p. 77f.
} 
instead of the original debtor. A credit insurance pays out - like a CDS at default of the debtor, but also in cases of payment delays and debtor-independent reasons like political risk like embargos. Instead of insuring the receivable only, the credit insurance insures the payment, i.e. also insures scenarios outside the receivable contract. The receivables are usually trade receivables whereas CDS reference debts are usually financial receivables (bonds, loans). The insurance liability only exists as long as the receivable is not paid, i.e. insurable interest is required. The same as for CDS, the debtor is not part of the credit insurance contract. Hence, a CDS is not a credit insurance because it covers less credit events, does not require insurable interest and is not based on trade receivables.

A second product that covers credit risk is the financial guarantee. A financial guarantee is a contract where the guarantor promises to reimburse a creditor for a loss caused by a specified debtor that failed on due payments from a debt instrument. ${ }^{19}$ In contrast to a credit insurance, the claim usually results from a financial receivable and not from a trade receivable. Similar to the credit insurance, but in contrast to CDS, a financial guarantee is legally linked to a claim ensuring the insurable interest. The link is of a subordinated nature, i.e. the guarantee automatically stops if the original claim does not exist anymore. Hence, a claim can exist without a guarantee (unguaranteed claim), but a guarantee cannot exist without the claim. Second, a guarantee is initiated by the debtor. By contrast, a credit insurance is initiated by the creditor. A CDS can be initiated by parties without any economic relation to the reference debt (neither being debtor nor creditor). ${ }^{20}$

We conclude that CDS are not insurance contracts under US law. Under UK law, CDS are legally not insurance contracts neither although for a very small group of CDs (with illiquid reference debt), final legal clarification would be needed. ISDA-CDS (the vast majority) are non-insurance contracts. CDS are not credit insurances because credit insurances require the insurable interest (usually) in form of a trade receivable. For the same reason they are not a financial guarantee.

\section{ACCOUNTING AND REGULATORY ANALYSIS}

From an accounting point of view, IFRS 4 prescribes the valuation of "Insurance Contracts" and IFRS 9 the valuation of "Financial Instruments". IFRS 4 explicitly states that credit derivative default contracts are not in the scope of IFRS 4, but of IFRS $9 .^{21}$ Hence, also accounting-wise, CDS are to be treated differently than insurance contracts.

Regulation-wise, CDS are not to be regulated as an insurance contract in the US. ${ }^{22}$ In UK, the FCA follows the legal definitions but admits that for very special cases the classification into insurance vs. non-insurance contracts might legally not be clarified yet. As the FCA needs to classify nevertheless, the FCA provides guidance ${ }^{23}$ beyond the legal cases. It states that in cases of doubt (i.e. CDS with illiquid reference debt), it will consider each case separately. Furthermore, the FCA notes that the classification insurance non-insurance cannot be derived from the economic nature of the transactions, i.e. transactions with the same economic nature might be classified differently. The FCA states that a contract does not fall in the insurance category if it is not described as insurance and does not contain insurance terms ${ }^{24}$ Currently, no case is known where the FSA has treated a CDS as insurance contract which is confirmed by FSA's Turner review ${ }^{25}$

Hence, also regulation-wise, CDS are not considered to be insurance contracts.

If CDS were regulated as insurance contracts, the product could only be sold by authorized insurance firms. As a consequence of that fact that they are not insurance contracts, the use of CDS (i.e. the product) is not constrained: virtually anybody can enter into a CDS for any reason. CDS interfere with regulation only if a

\footnotetext{
${ }^{19}$ See (IASB, 2010), Appendix A.

${ }^{20}$ See $(\mathrm{Ng}, 2010)$.

${ }^{21}$ This applies to all new credit derivative contracts. In the rare case that contracts have been valued as insurance contracts before, they can be still valued as such. See (IASB, 2010), B18(g).

${ }^{22}$ See (Dodd-Franck, 2010), Title VII, Subtitle A, Part II, §767.

${ }^{23}$ But no definitive legal advice as this can only be done by courts.

${ }^{24}$ See (FSA, The Perimeter Guidance Manual, 2012), p.9.

${ }^{25}$ The Turner review discusses a fictive product regulation of CDS. See (FSA, The Turner Review, 2009), p.109.
} 
counterparty is itself institutionally regulated (e.g. Banks by CRD IV, Insurance companies by Solvency II). By contrast, if a is held by unregulated entities (like hedge funds, Special Purpose Vehicles), their use is not restricted in the US nor in UK. ${ }^{26}$

After having derived that CDS are legally, accounting- and regulatory-wise not insurance contracts, we discuss the economic dimension of both instrument classes in the following section.

\section{ECONOMIC ANALYSIS}

\subsection{Economic Profile Of A Single CDS}

If one reduces the economic dimension of a CDS to the cash flows, CDS can be economically equivalent to a credit insurance if the protection buyer holds both the reference debt and the CDS. contracts.

Although cash flows might be equivalent, CDS differ in many other economic aspects from insurance

In particular, CDS are ...

1. ... written on a restricted set of debtors

2. ... priced mark-to-market- and not actuarially

4. ... accounted mark-to-market

3. ... traded

5. ... exposed to margin calls

6. ... predominantly concluded between banks

7. ... not restricted by the available issued reference debt

Note that none of these criteria are determinants for the legal form nor are they determinants for the cash flow at default, i.e. their potential protection effect. However, they are determinants for the risk profile prior to...to default of a single CDS and CDS portfolios. These profiles are substantially different to single insurance contracts and portfolios of insurance contracts.

\subsubsection{Restricted Set Of Insurable Entities}

For insurance policies, the number of covered individuals (life) and objects (non-life) is large as the insurance model is based on risk pooling and risk portfolio diversification. ${ }^{27}$ By contrast, CDS are usually only written on a small subset of economic entities like large corporates, sovereigns and other public sector entities for which credit risk information is publicly available. The current set of tradeable CDS names is around 10.000. The analogy of the restricted insurability in the CDS segment would be that life insurance contracts can only be done for VIPs or for a restricted set of publicly known objects (like the Golden Gate Bridge) in case of construction insurance.

The publicly available information about the creditworthiness of the debtor is important for a CDS, such that market pricing (also by agents that do not have any legal relationship to the debtor) is possible. This is important, as the reference debtor is not part of the CDS contract. As a consequence, it might not know the outstanding CDS volume on its debt. By contrast, for insurance contracts the insured is obliged to disclose all information that is relevant for the pricing to the insurer before the contract is made (principle of utmost good faith). The fact that the insured person (life insurance) or owner (non-life insurance) is part of the insurance contract

\footnotetext{
${ }^{26}$ The situation is different in Germany: in May 2010, the supervisory authority, BaFin, prohibited (=drastically regulated) to buy protection against the default of a public entity of a EUR-country without having any default exposure (= insurable interest). This approach has been brought to the European level and approved by the European Parliament as of November 15, 2011. It is expected to be implemented in all Member states by November 1st, 2012, subject to the approval by the European Council. See (BaFin, 2010), p. 8ff.

${ }^{27}$ Insurance companies might exclude persons with overly risky hobbies, professions or personalities.
} 
facilitates the disclosure requirement. As a consequence, the insured person/ owner exactly knows the insured amount on his life/ objects.

\subsubsection{Market-Priced And Actuarially Priced}

CDS spreads (the premium) should reflect the expectations of the protection buyer and seller on the probability of the credit event and the size of the payment (loss-given default). ${ }^{28}$ Both can be abbreviated as loss parameters. In this regard, CDS pricing takes similar parameters into account as pricing of insurance contracts. Depending on the insurance type, insurance premia are calculated on a pooled or individual basis. Pricing on a pooled basis means to use pooled (i.e. averaged) event probabilities and pooled loss payments. This is necessary for insurance firms with large numbers of insured persons/ objects (i.e. where pools of similar persons/ objects can be built). Other insurance types like a credit or project insurance are priced on parameters that have been individually estimated for the specific object/ project. CDS pricing is made on a stand-alone basis, i.e. only with the individual parameters of the reference debtor and without consideration of the existing position of the protection seller.

\subsubsection{Mark-To Market Accounting}

The valuation of insurance contracts is based on actuarial models (mark-to-model). The value changes if the payout parameters (probability and severity of insurance event) change. By contrast, CDS are usually valued mark-to-market, i.e. at their market value. This implies that daily changes in the market value directly affect profit and loss. But this also means that CDS are best to hedge reference debt or correlated debt positions that are also marked-to market. Also, an insurance contract with an expected loss valuation cannot be used to hedge an exposure that is marked-to-market. By contrast, a CDS can also be valued mark-to model if used to hedge an exposure of an illiquid reference debt.

\subsubsection{Tradeability}

In the case of insurance contracts, both the policy holder and the insurance company usually have the intention to hold the contract until maturity. ${ }^{28}$ In this respect, insurance policies are illiquid. Furthermore, no party enters into an insurance contract with the intention to sell or unwind the contract in the short term. CDS on the other hand are traded. Their tradeability results from the publicly observable information ${ }^{29}$ that is available on the largely restricted set of reference entities (as per point (1)). Based on daily changing market prices and the missing insurable interest, CDS positions can generate a profit in very short time also for the protection buyer. ${ }^{30}$ Hence, both CDS parties might enter a CDS with the intention to exit the position after some days. This implies that the (credit) risk can quickly and at low cost be transferred to other willing counterparties. As CDS markets are liquid, chains of CDS can quickly emerge. However, a chain of CDS is like a telescope sum: only the first protection buyer and the last protection seller are relevant for the question who assumes the final exposure. As long as CDS are bilaterally cleared over-the-counter (OTC), it is very difficult to track who is the final protection seller that assumes the default risk. The use of central counterparties (CCP) implies that the second CDS party is always the central counterparty. Consequently, the net exposure of each CDS market participant with the central counterparty is the net exposure/ coverage for each CDS market participant answering the question of the final exposure.

\subsubsection{Mark-To Market Accounting}

The valuation of insurance contracts is based on actuarial models (mark-to-model). The value changes if the payout parameters (probability and severity of insurance event) change.

\footnotetext{
${ }^{28}$ (Life insurance) Policy holders might be able to sell their insurance prior to maturity to third parties. Insurance companies might sell portfolios of policies (or tranches of the portfolio loss distribution) to re-insurance companies. However, the initial and most common intention of both parties is the holding of the policy till maturity.

${ }^{29}$ The majority of CDS entities are listed companies.

${ }^{30}$ Note that the policy holder usually cannot make a profit as the insurance only pays up to the suffered loss. By contrast, the CDS payoff can constitute a profit for the protection buyer at the absence of insurable interest.
} 
By contrast, CDS are usually valued mark-to-market, i.e. at their market value. This implies that daily changes in the market value directly affect profit and loss. But this also means that CDS are best to hedge reference debt or correlated debt positions that are also marked-to market. Also, an insurance contract with an expected loss valuation cannot be used to hedge an exposure that is marked-to-market. By contrast, a CDS can also be valued mark-to model if used to hedge an exposure of an illiquid reference debt.

\subsubsection{Exposed To Margin Calls}

As a consequence of their mark-to-market valuation, CDS are subject to margin calls to reduce counterparty risk. ${ }^{31} \mathrm{~A}$ margin call is a mechanism that converts value risk into liquidity risk. Hence, the risk for a well-capitalised CDS counterparty is primarily a shortfall of liquid assets as potential losses are converted into collateral calls. This mechanism was a main driver for the quasi-failure of the US insurance company AIG. AIG sold large volumes of protection on super senior tranches of pools of loans and debt securities. ${ }^{32}$ Due to the deteriorated credit worthiness of the reference debtors, AIG accounted \$ 26.5 billion mark-to-market losses in their CDS book. For these losses, AIG had posted \$ 15.7 billion collateral by June 2008, 16.5 billion by mid-August and $\$ 23.4$ billion by September 12th. The posting of additional collateral would have been expected due to further CDS losses, and also due to AIG's downgrade and associated problems with the roll-over of its commercial paper, problems which led to the final $\$ 182$ billion bailout. ${ }^{33}$ This value-to-liquidity conversion with its implied large liquidity needs is very different to the liquidity risks an insurance company is exposed to.

\subsubsection{CDS Predominantly Exist Between Banks}

Insurance policies are usually contracted between insurance companies (protection seller) and a noninsurance party (protection buyer). Only a small fraction of insurance contracts, re-insurance contracts, are intrasector. By contrast, a substantial portion of CDS are sold intra-sector between banks as suggested by the "interbank portion" of Figure 3.

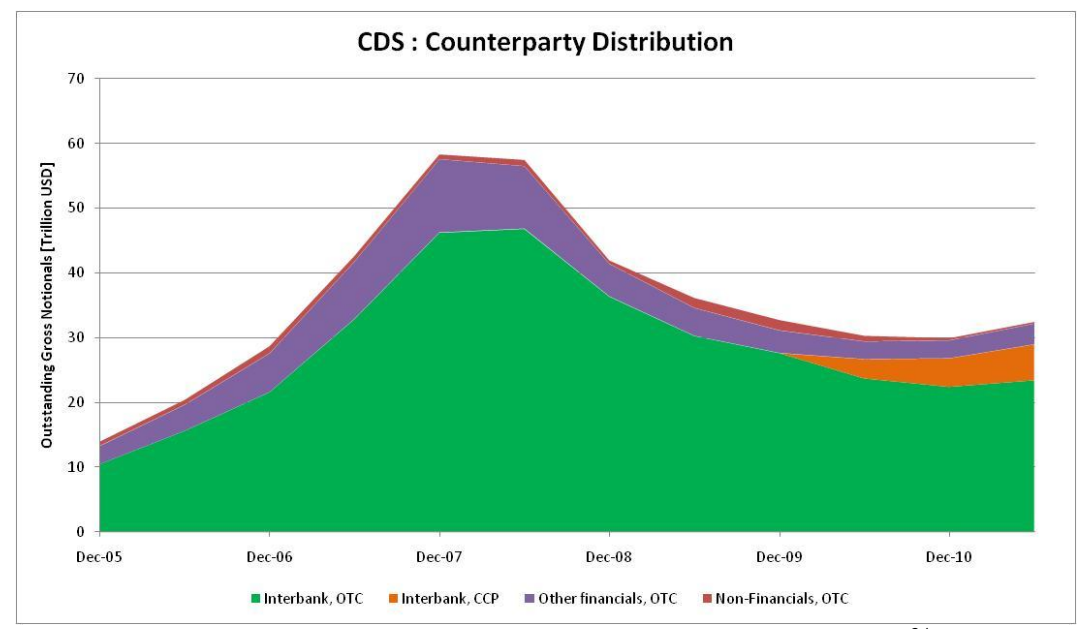

Figure 3: CDS Volume Distribution Across Counterparties ${ }^{34}$

The counterparties are not only concentrated within the banking sector, but remain concentrated intrasector: the five largest dealers (accounting for 50\% of gross notional amounts outstanding) are banks. ${ }^{35}$

\footnotetext{
${ }^{31}$ See (ECB, 2009), p.20.

${ }^{32}$ See (AIG, 2007), p.11.

${ }^{33}$ See (FCIC, 2011), p. $344 \mathrm{ff}$.

34 "OTC derivatives market activity in the first half of 2011", November 2011, Bank for International Settlements (BIS). Although notional information are available since June 2004, reliable counterparty information are only captured since Dec 2005.

${ }^{35}$ See (Bundesbank, December 2010), p. 47, footnote 13.
} 
Interbank CDS contracts form - similar to interbank lending and depositing - a conditional network (one for each reference debt) that converts into an unconditional network if the credit event is triggered (Cont, 2010). The contingency of CDS networks is different to the unconditional network that interbank loans and deposits form. However, it has the same relevance for systemic risk as funded, unconditional networks. Considering second round effects (e.g. that the default of one reference debt/ network triggers the default of another reference debt/ network), there exist considerable interdependencies between the conditional networks.

\subsubsection{Unlimited Volumes}

The global amount of insurable interest is limited by the value of insurable objects and persons.

As both parties of a CDS do not need any relation/ exposure to the reference debt (rather than simply cover losses), the potential outstanding CDS volume is not limited by the volume of outstanding reference debt. The fact that the protection buyer has the possibility to make a (short -term) profit (and not only to cover losses) increase the incentive to enter into CDS (beyond the outstanding exposure). As an example, (Stulz, 2010) reports that the outstanding volume of CDS on Ford Motor Company at May 152009 was around 1.4 times higher than the total debt. As a CDS generates exposure (a risk) for the protection seller without the protection buyer having had an exposure (risk), the resulting exposure has been generated "out of nothing". On an aggregate level (e.g. on the banking sector level), these exposures cancel out and only net exposures remain. However, on an entity level, the protection seller now assumes a risk (for the protection buyer) that did not exist before. If the protection buyer is a regulated entity (e.g. a bank or an insurance company), it has to reserve capital (and liquidity if the CDS is margined) for that risk. Hence, the risk "out of nothing" has real consequences in terms of capital and liquidity for regulated entities. If capital/ liquidity reserves are very differently distributed to CDS net exposures, CDS generate instability "out of nothing".

\subsection{Systemic Risk Potential Of CDS And Insurance Contracts}

An important source of systemic risk is bilateral exposures. As argued, the majority of CDS is contracted intra-sector. This implies that CDS counterparties are closely interconnected. Depending on the CDS exposure distribution, the networks can be stable (low systemic risk) or unstable (high systemic risk) to exogenous shocks. ${ }^{36}$ As the major CDS counterparties also figure as major reference entities, endogenous shocks and mutual reinforcements between counterparty and credit risk are possible. Because CDS are tradeable, the structure of the network and therefore the systemic risk can quickly change. Additionally, because of margin calls, value changes materialize quickly as liquidity changes and the time to a potential distress shortens. Last but not least, because of the absence of an insurable interest, CDS exposures are not limited to the outstanding debt but can be at multiples of the insurable debt. The intra-sector contracts, the tradeability, the missing insurable interest and the margin calls imply that CDS have a much higher systemic risk potential than insurance contracts, which are not intra-sector, not tradeable and whose exposure is limited to potential losses.

\section{CONCLUSION}

The motivation for this article has been the observation that CDS are often labelled "default insurance". We show that CDS might protect against a default, but they are not insurance contracts from a legal, accounting and regulatory perspective. In the US, an explicit legal statement prevents CDS from being considered insurance contracts. In the UK, the Potts opinion has been followed and so far no CDS has ever been classified as insurance in court. However, for the small set of CDS with illiquid reference debt, a court decision would be desirable to legally confirm what is so far an opinion (and market standard).

Economically, CDS can be equivalent to insurance contracts if the protection buyer holds both the CDS and the reference debt at the same time. However, other economic aspects beyond the pure cash flows lead to a very different risk profile of CDS compared to insurance contracts. CDS imply daily P\&L-changes as they are traded and marked-to-market. By contrast, insurance contracts do not exhibit daily P\&L-changes due to their mark-to-model

\footnotetext{
${ }^{36}$ For a study how the network structure impact the network stability, see (Georg, forthcoming).
} 
valuation where model parameters usually do not change with daily frequency. Furthermore, CDS are exposed to margin calls converting value risk into liquidity risk. Thus, CDS counterparties do not only need sufficient capital (reserves) but also adequate liquidity (reserves). Finally, the CDS market is highly oligopolistic, i.e. the main portion of CDS is contracted between (a few) banks. CDS of each reference entity form a (conditional lending) network across banks. The network stability varies with the distribution of capital-and liquidity reserves versus net CDS exposure. As the CDS volume is not limited to the outstanding debt volume, the net exposure (and therefore the risk profile) of the CDS networks is also unlimited. At its extreme, this risk accumulation can decrease resilience whereas insurance activities with insurable interest usually increase resilience by risk pooling. Hence, CDS can be the source of important systemic risk whereas insurance contracts generally cannot.

Instead of using "CDS are default insurance", we propose to use "CDS are default protection". If one wants to use the term "default insurance", we propose to use "CDS work as default insurance if the protection buyer also holds the reference debt". The "are" refers to the legal dimension and the "work as" to the economic dimension.

\section{AUTHOR INFORMATION}

Christian Schmaltz, Aarhus University, Aarhus (Denmark). E-Mail Address: Chsch@Asb.Dk; And True North Institute, London (UK). E-Mail Address: Christian.Schmaltz@Tninstitute.Eu. (Corresponding Author)

Periklis Thivaios, University Of The Witwatersrand, Johannesburg (South Africa).

E-Mail Address: Periklis.Thivaios@Wits.Ac.Za; And True North Partners, London (UK). E-Mail Address: Periklis.Thivaios@Tnpartners.Eu

\section{REERENCES}

1. AIG. (2007). Annual Report.

2. $\quad$ Allianz. (2010). Annual Report. Allianz Group.

3. $\quad$ BaFin. (2010). BaFin Quarterly Q4/10.

4. Baranoff, E., Brockett, P. L., \& Kahane, Y. (2009). Risk Management for Enterprises and Individuals. Flat World Knowledge, Inc.

5. BCBS. (2010). Basel III: A global regulatory framework for more resilient banks and banking systems. Basel: BIS.

6. BCBS. (2011). Global systemically important banks: assessment methodology and the additional loss absorbency requirement. Basel: BIS.

7. BCBS. (2006). International Convergence of Capital Measurement and Capital Standards. Basel: BIS.

8. $\quad$ BCBS. (2009). Revisions to the Basel II market risk framework. Basel: BIS.

9. Brown, A. (2010, April 13). Naked CDs and Buying Fire Insurance on Your Neighbour's House. Retrieved from www.quantnet.com: www.quantnet.com/cds-versus-insurance/

10. Bundesbank. (December 2010). Monthly Report.

11. Cont, R. (2010, July). Credit default swaps and financial stability. Banque de France: Financial Stability Review, pp. 35-43.

12. Dodd-Franck. (2010). Dodd-Frank Act, Title VII, Subtitle A, Part II, \$722(b).

13. $\quad$ ECB. (2009). Credit Default Swaps and Counterparty Risk.

14. European Union. (2009, November 25). Directive of the European Parliament and of the Council on the taking-up and pursuit of the business of insurance and reinsurance (Solvency II) (recast). Strasbourg: European Union.

15. FCIC. (2011). The Financial Crisis Inquiry Report. National Commission on the Financial and Economic Crisis in the United States.

16. FSA. (2002). Cross-sectorRisk Transfers. London: Financial Services Authority.

17. FSA. (2012). The Perimeter Guidance Manual.

18. FSA. (2009). The Turner Review. London.

19. Georg, P. (forthcoming). The Effect of Interbank Network Structure on Contagion and Common Shocks. Journal of Banking and Finance . 
20. Harding, P. C. (2004). A Practical Guide to the 2003 ISDA Credit Derivatives Definitions. Euromoney Books.

21. IASB. (2010). International Financial Reporting Standard 4: Insurance Contracts. London: IFRS Foundation.

22. Juurikkala, O. (2011). Credit Default Swaps and Insurance: Against the Potts Opinion. Journal of International Banking Law and Regulation, Vol. 26(3) , pp.128-135.

23. Juurikkala, O. (2011). Credit Default Swaps and Insurance: Against the Potts Opinion. Journal of International Banking Law and Regulation, 128-135.

24. Law Commission. (2008). Insurable Interest. Insurance Contract Law Issues Paper 4 1-92.

25. Ng, L. (2010). Credit default swaps, guarantees and insurance policies: same effect, different treatment? Butterworths Journal of International Banking and Financial Law, 664-666.

26. Stulz, R. M. (2010). Credit Default Swaps and the Credit Crisis. Journal of Economic Perspectives , (24-1) 73-92. 